\title{
Entre el aislamiento y las brechas digitales: sistematización de experiencia de acompañamiento socioemocional en personas mayores de Temuco, Chile, en tiempos de COVID-19
}

\author{
G. Bernarda Aedo-Neira \\ Trabajadora social \\ Universidad Católica de Temuco. Temuco, Chile \\ https:/ / orcid.org/0000-0003-1792-6347・ bernardaaedoneira@gmail.com
}

Resumen

Este artículo sobre sistematización de experiencia presenta el trabajo realizado dentro del proyecto de acompañamiento socioemocional, desarrollado durante el año 2020 en el contexto del COVID-19 que afectó mayoritariamente a las personas mayores, el cual da cuenta de cómo el aislamiento y las brechas digitales juegan un papel fundamental en la salud física y mental de las personas.

Uno de los cuestionamientos principales es: ¿Cómo el aislamiento y las brechas digitales afectaron la salud mental de las personas mayores en tiempos de pandemia? Para responder a esta interrogante se realizó una investigación cuantitativa, por medio de técnicas como entrevistas, encuestas, registros escritos, talleres, revisión de artículos y seminario.

Los resultados se ven reflejados por medio de llamadas telefónicas realizadas por un grupo de estudiantes en práctica a las personas mayores que participaron en el proyecto, encontrando aquí los efectos negativos que produjo el aislamiento en su diario vivir y las dificultades encontradas por ellos mismos al no saber manejar los medios digitales para poder comunicarse con sus familiares y amigos.

Palabras clave: Personas mayores; Aislamiento; Brechas digitales; COVID-19; Acompañamiento socioemocional.

Recibido: 23/08/2021 | Aprobado: 24/09/2021 | Publicado: 01/01/2022

cc) (i) Esta obra está bajo una Licencia Creative Commons Atribución-NoComercialCompartirIgual 4.0 Internacional.

Financiación o proveniencia del artículo: Artículo derivado del Proyecto de sistematización de acompañamiento socioemocional en personas mayores de Temuco realizado en el periodo agosto - diciembre 2020 avalado por la carrera de Trabajo Social Universidad Católica de Temuco.

¿Cómo citar este artículo? / How to quote this article?

Aedo-Neira, G. B. (2022). Entre el aislamiento y las brechas digitales: sistematización de experiencia de acompañamiento socioemocional en personas mayores de Temuco, Chile, en tiempos de COVID-19. Prospectiva. Revista de Trabajo Social e intervención social, (33), 33-56. doi: 10.25100/ prts.v0i33.11540.

e-ISSN: 2389-993X • https:/ / doi.org/10.25100/prts.v0i33.11540 •Universidad del Valle - Cali, Colombia 
Aedo-Neira

\title{
Between Isolation and Digital gaps: Systematization of an Experience of Socio-emotional support in Elderly People of Temuco, Chile, in Times of COVID-19
}

\begin{abstract}
This article on systematization of experience shows the work carried out within the socio-emotional accompaniment project developed during 2020 in the context of COVID-19, in which elderly people were mainly affected. It shows how isolation and digital gaps play a fundamental role in people's physical and mental health.

One of the main questions is: How did isolation and digital gaps affect the mental health of elderly people in times of pandemic? To answer this question, a quantitative research was carried out through techniques such as interviews, surveys, written records, workshops, article review and seminars.

The results are reflected by means of telephone calls made by a group of students in practice to the elderly people who participated in the project, and which revealed the negative effects that isolation produced in their daily lives and the difficulties encountered by them because they do not know how to handle digital media to be able to communicate with family and friends.

Keywords: Elderly people; Isolation; Digital gaps; COVID-19.

Sumario: 1. Introducción, 2.Contextualización: Desarrollando las prácticas iniciales y profesionales de estudiantes en pandemia, 3. Fundamentación teórica para la sistematización, 3.1 Personas mayores: entre el confinamiento y el aislamiento en tiempos de COVID-19, 3.2 Efectos de las brechas digitales en personas mayores en tiempos de COVID-19, 4. Metodología, 5. Hallazgos, 5.1 Resultados de la experiencia de trabajo en el proyecto, 5.2 Desafíos para el Trabajo Social, 6. Conclusiones, 7. Referencias bibliográficas.
\end{abstract}




\section{Introducción}

Debido a las condiciones sociosanitarias vividas en 2020 los y las estudiantes se vieron imposibilitados(as) de poder llevar a cabo sus prácticas, con personas mayores en las instituciones comunitarias de la ciudad de Temuco en la región de la Araucanía. Frente a esto el grupo de estudiantes y docente encargada de las practicas, tomaron como decisión el buscar nuevas herramientas y métodos que les permitiera el poder acompañar a este grupo etario el cual se vio con mayores prohibiciones y afecciones a la salud.

A continuación, se comentará como se desarrolló el proyecto de acompañamiento socioemocional y se explicara como los factores de aislamiento y brechas digitales, jugaron un papel fundamental en la salud física y mental de las personas durante los meses de encierro. Que tal como lo muestra la siguiente sistematización afectaron directamente a la población mayor participante de este proyecto de acompañamiento socioemocional vía telefónica.

Aquí se muestra como la situación sociosanitaria inesperada vivida a nivel mundial a causa del virus denominado Coronavirus o COVID-19, provoco que estudiantes de tercero, cuarto y quinto año de la carrera se vieran imposibilitados(as) de cumplir con sus prácticas en los distintos centros de forma presencial. Especialmente viéndose afectado el grupo de estudiantes que desarrollarían sus prácticas en los centros comunitarios de "adultos mayores", de la localidad de Temuco, con quienes tenían contemplado realizar su trabajo con este grupo etario.

\section{Contextualización: desarrollando las prácticas iniciales y profesionales de estudiantes en pandemia}

A principios de enero del 2020, se informó a cada estudiante de la carrera de Trabajo social en la Universidad Católica de Temuco, los centros en donde tendrían que desarrollar sus prácticas. Estas iniciarían en el mes de abril, con un trabajo presencial con la población elegida por cada estudiante de la carrera. Estos centros, si bien fueron autogestionados o designados por las postulaciones realizadas por los(as) estudiantes de la carrera, logró que cada uno pudiera trabajar en su área de interés; ya sea educación, salud, envejecimiento, entre otros.

La elección de abordar la temática de envejecimiento y vejez recae en el interés personal por el tema y la relación que esta tenía con la tesis de grado, que se realiza de forma paralela, cuya intención es estudiar las relaciones intergeneracionales existentes y los efectos para el envejecimiento activo que estas presentaban. Por estos motivos, se postuló al centro de personas mayores para tener una relación más directa con la "población de muestra" y 
la temática de interés. Sin embargo, al no poder realizarse este trabajo con las personas de manera presencial, se optó por un cambio de metodología y enfoque de las prácticas.

Según el Observatorio Social (2020), el último Censo realizado en el año 2017, indica que en Chile existían 2.9 millones de personas mayores, y se proyecta que el envejecimiento social acelerado que presenta el país se refleje, para el 2050, en un aumento importante en este grupo etario de mayores de 60 años, el cual podría llegar a 6.9 millones, lo que corresponderá aproximadamente al 31,2\% de la población general del país. Frente a esta imagen de envejecimiento acelerado que pasa la población de Chile, nació el interés de investigar e indagar en las temáticas de envejecimiento y vejez, promoviendo herramientas y políticas públicas que desarrollen y beneficien el envejecimiento activo de la población a nivel nacional.

No obstante, a causa del contexto sociosanitario vivido a nivel mundial, nacional y regional que afectó a la población, sin importar grupos etarios o clases sociales, las prácticas no se llevaron a cabo con normalidad. Según la Pontificia Universidad Católica de Chile (2020), de acuerdo con un informe de la ONU en el mes de mayo, el 95\% de las muertes por COVID -19 en países de Europa corresponde al grupo etario de personas mayores de 60 años, mientras que en China esta cifra fue de un $80 \%$. Además los datos indicaron que en Estados Unidos los mayores de 65 representan el 80\% de los fallecimientos totales del país. En Chile, al mes de junio, el 18\% de las muertes por COVID-19 corresponde a personas entre 60 y 69 años, un 79\% tenía entre 70 años y otro 26\% tenía más de 80 años, lo que deja una imagen completamente negativa frente al virus.

Todos estos datos fueron claves para el cambio metodológico en el proceso académico frente a la imposibilidad del trabajo presencial, por las distintas cuarentenas impuestas en cada una de las comunas del país que afectó principalmente a la población mayor, siendo el grupo que tuvo mayores resultados fatales al momento de contraer el virus y las medidas para resguardar su salud fueron más estrictas. Debido a esto, el proceso de trabajo se modificó, de uno presencial y directo con las personas en los centros a un trabajo completamente online, mediante el teletrabajo en el cual las reuniones se realizaron por medio de Meet de Google y WhatsApp, donde las estudiantes se reunían con la profesora para organizar el proyecto, además de mantener el contacto telefónico con las personas mayores durante el acompañamiento.

Anteriormente, el proceso de prácticas se llevaría a cabo dentro de los centros comunitarios dependientes de la Municipalidad de Temuco, pero cuando esto no se logró debido a la situación vivida en el país y las distintas comunas, se conformó el "Grupo de Estudio y Trabajo de Envejecimiento y Vejez", con el fin de llevar adelante el proyecto de acompañamiento socioemocional vía telefónica con un grupo de personas mayores 
voluntarios pertenecientes a la Asociación de Funcionarios Jubilados de la UCT y Organización de Personas Mayores-Centros Comunitarios de la Municipalidad.

Cada estudiante se hizo cargo de un pequeño grupo, conformado de tres personas mayores, con los que se comunicaban una vez por semana vía telefónica. Las llamadas telefónicas tenían una duración aproximada de 45 a 60 minutos, en donde ellos compartían con las estudiantes sus inquietudes y necesidades. Cada estudiante realizó entre 4 a 5 sesiones de llamadas para poder producir un ambiente de intercambio mutuo. En primera instancia, se comenzó con un acercamiento, en la segunda sesión se compartieron las experiencias de cómo se vivió la crisis sociosanitaria, en la tercera sesión se desarrollaron lazos intergeneracionales y finalmente en la cuarta etapa, se recogieron los elementos más importantes de cada una de las llamadas compartiendo cuáles fueron los nuevos conocimientos producidos. Se cerró con un seminario que contó con la participación de las estudiantes, la docente encargada, la jefa de carrera y las personas mayores participantes. Se reflexionó sobre lo positivo y negativo de la experiencia vivenciada en el acompañamiento socioemocional.

A través de las llamadas telefónicas, se observó cómo el decaimiento y agotamiento psicológico que vivenciaban las personas mayores se empezó a notar en cambios físicos y psicológicos como: la falta de sueño, falta de apetito, estrés o cambios de ánimo que causaron y siguen causando distintos malestares. El acompañar a las personas mayores, en estas instancias de alguna $\mathrm{u}$ otra forma, dentro de lo que respecta la crisis sociosanitaria, crea y refuerza los lazos intergeneracionales, de acompañamiento y aprendizaje mutuo entre las profesionales en formación y las personas mayores participantes. La importancia del apoyo emocional que se intentó brindar durante los meses de encierro, permitió comprender de mejor manera cómo las personas que se vieron afectadas emocionalmente, debido a la situación de incertidumbre vivida, en donde ellos mismos notaron el cambio en sus rutinas diarias o de alimentación, se sintieron afectados en distintos ámbitos y no lograron desenvolverse dentro de la normalidad de su diario vivir durante los meses de encierro.

\section{Fundamentación teórica para la sistematización \\ 3.1 Personas mayores: entre el confinamiento y el aislamiento en tiempos de COVID-19}

Para comenzar, se debe tener en cuenta que este virus afectó a cada persona en distintos niveles: emocional, laboral, familiar y social. Con esto, se tiene que considerar el cambio abrupto en la rutina diaria que sufrió cada persona, especialmente las personas mayores. 
En Chile, se declaró el estado de excepción el día 18 de marzo de 2020, con el fin de resguardar la salud de la ciudadanía, en donde cada una de las comunas del país entró en cuarentena obligatoria. De esta forma, se comenzó a trabajar con el plan paso a paso, siendo una estrategia gradual para enfrentar la pandemia según la situación sanitaria de cada zona. Este plan consta de 4 pasos: a) cuarentena; b) transición; c) preparación y d) apertura. Con estas restricciones las personas mayores, en la mayoría de los casos, se vieron aislados, viviendo sin un familiar o compañero(a), quien pudiera ser su soporte para sentirse acompañado durante los meses de encierro, siendo los(as) "adultos mayores (...) especialmente vulnerables ante las medidas de cuarentena y aislamiento social, teniendo en cuenta que en esta etapa se reducen las redes de apoyo social y disminuye la participación" (Broche-Pérez, Fernández-Castillo y Reyes-Luzardo, 2020, pp. 6-7). Por lo tanto, ellos(as) no pudieron participar de sus actividades diarias como junta de vecinos, talleres, etc. al verse reducidas las redes de apoyo con la que contaban en estos espacios debido al encierro, vemos cómo emocionalmente comenzaron a debilitarse por no contar con este apoyo en sus vidas.

Durante el periodo de cuarentena pasaron por distintas emociones, varios sintieron una sensación de soledad, la que mayormente se pronunció en mayores de 65 años, quienes se vieron más afectados(as) que otros grupos etarios al sentirse incomprendidos(as) o asustados(as) por la difícil situación que se estaba viviendo a nivel mundial. Según GajardoJauregui (2015), “La soledad en la vejez responde (...) a una condición de estado emocional que se produce cuando una persona se siente distanciada de, o incomprendido o rechazado por otros" (p. 202).

Al momento de llegar a una edad avanzada, podemos ver cómo muchas personas comienzan a sentirse solos(as) por diversos motivos, presentando sentimientos negativos, que durante este aislamiento se pronunciaron aún más en aquellos(as) que viven solos(as) o sufren menor movilidad, que se vio reflejado en este proceso de investigación y generación de proyecto, siendo una preocupación importante trabajar con la soledad que pasaron los(as) participantes.

La importancia del apoyo emocional resultó ser esencial en las condiciones de encierro, más aún, cuando los datos indican que existe un gran índice de personas mayores con depresión en el país, el Servicio Nacional del Adulto Mayor (2019), nos indica que según las cifras del Ministerio de Salud, alrededor de 1.800 personas se suicidan al año en nuestro país, tasa que es liderada por las personas mayores, pero en particular se puede apreciar cómo los intentos de suicidio a partir de los 80 años incrementaron en un 133\%, siendo este el grupo etario donde más creció esta cifra en los últimos años. También, se menciona en este informe, que el siguiente grupo que presenta altos índice de suicidios en el país fluctúa entre las personas de 60 y 69 años que incrementaron un 76\% en el último tiempo. 
Según la Mesa Social COVID-19 (2020), las personas mayores sufrieron algunos efectos considerados "normales" frente a la situación vivida, tales como: miedo, ansiedad, rabia, insomnio o falta de concentración, mientas que también se mencionan los efectos preexistentes con los que viven diariamente como: trastornos adaptativos, trastornos del ánimo, trastornos de ansiedad, trastorno por estrés agudo y suicidio. Dichos efectos o enfermedades patológicas se acentuaron aún más con el paso de los meses; frente a esta imagen general proyectada, se preparó una forma de abordar la situación que vivenciaron aquellas personas que participaron del proyecto de acompañamiento, quienes mencionaron varios de los efectos expuestos por la Mesa Social COVID-19, producidos por el contexto de confinamiento sufrido de marzo a septiembre por mayores de 65 años, debido a todas las prohibiciones y obligaciones impuestas donde se les impidió el poder desplazarse libremente por sus comunas con el fin de evitar contagios. Todo esto causó un decaimiento y agotamiento psicológico que comenzó a hacerse presente al momento de ver detenidas sus rutinas establecidas, especialmente con el grupo de personas mayores del proyecto, quienes asistían a diversas actividades que les permitían mantenerse activos. Incluso las rutinas diarias en cuarentena se volvieron tediosas durante los meses de encierro y aislamiento, en donde no tuvieron contacto con otros.

La académica Susana González, de la Pontificia Universidad Católica de Chile (2020), comentó que durante el período de encierro, se observó cómo se agravaron los casos de demencia o memoria, por estos mismos factores de aislamiento que vivieron las personas mayores y mencionó cómo fue necesario el poder acompañarlos(as) durante este periodo de aislamiento, en donde la tecnología fue la mejor aliada para estar junto a nuestras familias, pero para quienes tienen complicaciones con ésta, pudo ser su peor enemiga al no poder manejar estas herramientas viviendo solos(as) y sin saber cómo utilizar un celular o un computador para mantener la comunicación con familiares y amigos(as).

Ante este escenario, cabe mencionar la importancia de la salud mental y el autocuidado, que es la mejor manera de resguardar la salud psicológica de cada individuo, en especial cuando estos viven solos(as). Se debe prestar atención a las necesidades que ellos presentan al no poder tener contacto con sus seres queridos, amigos o vecinos, lo que provoca que un número significativo de ellos se sienta apartado, con sentimientos de pena, angustia, fatiga, depresión o desánimo. Es por esto que el poder ser responsables con nuestro autocuidado, nos permite mantener una mejor calidad de vida, "el autocuidado está vinculado con las prácticas cotidianas de salud y con las decisiones que tomamos respecto de ella, estas prácticas tienen el propósito de reforzar, restablecer o imponer la salud o bien prevenir la enfermedad" (Guzmán-Olea et al., 2017, p. 12). El trabajo con las personas mayores, más aún en tiempos de COVID-19, se vuelve fundamental, tomando en cuenta las consecuencias negativas por las que han pasado en los últimos meses, tanto en lo emocional como en lo físico, frente a todos estos pensamientos y sentimientos negativos con los que han vivido. 
Es importante poder apoyarlos para sobrellevar de mejor manera la presión y tensión con la que conviven diariamente estando mayormente expuestos, "a una inadecuada protección (...) a sentir frustración, a sufrir discriminación (...) pérdida del contacto con la familia y al agotamiento físico y mental" (Lozano-Vargas, 2020, p. 52). Frente a la realidad social con la que convivieron día a día durante este último año, entre la incomprensión y el aislamiento social, presentando secuelas a largo plazo, en algunos casos, donde las personas sufrieron mayores secuelas. En lo que respecta a su salud mental presentaron síntomas como estrés, ansiedad, depresión o frustración. El acompañamiento socioemocional que se realizó durante este año académico permitió acompañar de una forma cercana a las personas mayores. De esta forma, el proyecto entregó el apoyo emocional necesario a cada uno de los participantes, quienes indicaron lo importante que es volver a reproducir estas experiencias, donde valoraron el trabajo y la participación de cada una de las estudiantes que trabajaron en el proyecto, frente a la preocupación mostrada semana a semana para entregar el mejor apoyo a cada una de las personas mayores ante sus necesidades.

\subsection{Efectos de las brechas digitales en personas mayores en tiempos de COVID-19}

Las experiencias vividas en el segundo semestre, mediante el acompañamiento telefónico realizado, ayudó a observar algunas de las dificultades experimentadas por las personas mayores dentro del aislamiento que se lograron detectar a causa de las prohibiciones de desplazamiento, vinculadas directamente a las brechas digitales que presenta gran parte de la población mayor. Uno de los problemas a los cuales se enfrentaron fue el no saber o poder solicitar algún bono como por ejemplo: el bono de Emergencia COVID-19, Ingreso Familiar de Emergencia, Plan de Ayuda para el Pago de Cuentas Básicas, Voluntariado "Yo Te Ayudo" o Retiro Previsionales. El poco acceso a internet o computadores, les hizo imposible poder solicitar estos beneficios que el gobierno dispuso para ayudar a la población durante estos meses de crisis.

Según la Fundación País Digital (2018), el grupo de personas entre 20 a 24 años es el que presenta mayor uso de internet, llegando al 94,5\% de la población en ese tramo etario. Por el contrario, el grupo que menos lo utiliza es el que está por sobre los 80 años, siendo sólo el 9,8\% el que hace uso de la red. Justamente, este grupo etario es quien más problemas ha presentado al no saber usar internet, provocando que las personas mayores comiencen a sentir el peso del reciente aislamiento al no poder acceder a beneficios estatales, el no tener contacto directo con las demás personas, el presentar dificultades para comunicarse con los demás por medio de celulares, computadores o no tener acceso a internet lo que es de una utilidad fundamental dentro de la realidad social actual.

Algunas redes fundamentales para trabajar o informarse fueron WhatsApp, Meet, Instagram y Zoom. Estas aplicaciones fueron en muchos casos una fuente de información 
positiva de todo lo que estaba sucediendo, pero también presentaron una connotación negativa a la hora de informar noticias, que a diario escucharon las personas generando un sentimiento de pánico al escuchar todos los días las cifras de contagios. Sin embargo, estas herramientas y redes sociales fueron primordiales al momento de compartir información sobre seminarios, beneficios estatales, entre otros.

Desde hace algunos años, en comercios como supermercados, estaciones de servicio, farmacias e incluso en pequeños almacenes cuentan con el pago por medio de tarjetas o incluso con aplicaciones telefónicas, con las que fácilmente se puede acceder a los pagos de estos servicios facilitando o dificultando la vida de las personas. Tomando en cuenta que los bonos estatales o pago del retiro del 10\% de las AFP durante estos meses fue directamente a las cuentas bancarias de los chilenos, se puede ver la importancia que estos medios tienen en la realidad actual, en donde el uso del internet fue fundamental para solicitar salvoconductos ya sea para la realización de trámites, compras de insumos o incluso el pago de servicios básicos.

Pero ¿qué pasa con ese pequeño grupo de personas mayores que no tiene un buen manejo de las redes sociales o herramientas tecnológicas? Es decir, con aquellos que viven solos teniendo menos posibilidad de acceder a estas herramientas tan útiles durante el encierro por las cuarentenas, dejando a un sector vulnerable frente a la realidad social de una comunidad que solo se mueve por el mundo digital. Debemos recordar que "la brecha digital está muy lejos de ser superada, aún en las sociedades de alto acceso (...) requiere de acciones específicas a partir de las políticas públicas (...) que promuevan y acompañen" (Rivoir, Morales y Casamayou, 2019, p. 297). Mientras en todas las localidades y comunas no se tenga un buen acceso a internet, las brechas digitales no serán zanjadas, continuarán existiendo aquellos que van quedando atrás de una sociedad que avanza a pasos agigantados a la modernización; es cuando las políticas públicas deben centrar su interés en poder participar y resolver estos problemas, en especial con aquellos mayores que no saben manejar las nuevas tecnologías.

Las brechas digitales hoy en día dificultaron el diario vivir de las personas mayores, más cuando a causa de este virus los celulares son nuestro más grande apoyo, los "móviles se utilizan (...) para chatear con los amigos, ponerse en contacto con familiares y amigos o comunicarse con otras personas conocidas (...) que permite a los usuarios estar en contacto a cualquier hora y en cualquier lugar" (Sabater-Fernández, Martínez-Lorea y Campión, 2017, p. 1596). Como se menciona, permiten la conectividad a cualquier hora y en cualquier lugar, ya sea, en caso de emergencia o simplemente para sentirnos acompañados transformándose en una necesidad esencial, más cuando a algunas personas mayores que viven solas se les hace más complejo el poder comunicarse con quienes están lejos. 
Por otro lado, existen otras brechas significativas e importantes como la accesibilidad que presenta la población a estas herramientas dentro del continente:

En 2019, el 66,7\% de los habitantes de la región tenían conexión a Internet. El tercio restante tiene un acceso limitado o no tiene acceso a las tecnologías digitales debido a su condición económica y social, en particular su edad y localización. (Comisión Económica para América Latina y el Caribe [CEPAL], 2020b, p. 2)

En Latinoamérica, aún existen muchos sectores donde las personas no cuentan con accesibilidad a internet o la señal es muy débil, esto se debe a los propios problemas demográficos existentes en las distintas zonas rurales de los países que impiden mejorar estas cifras. Entre estos tres factores a considerar se menciona tanto lo económico, lo etario y la localización en que se encuentra esta parte de la población mayor, dentro de este tercio considerable de la población que tienen mayores problemas de conexión. Esto debe ser una preocupación en la agenda social de los gobiernos, más aún cuando los avances tecnológicos nos llevan en dirección a una sociedad conectada.

Cabe mencionar que, en algunos casos, "La falta de recursos económicos es un factor fundamental en el acceso a internet. Los jubilados mayores de 64 años, los parados, los residentes en áreas rurales (...) son los grandes exiliados de internet y de sus ventajas" (Sabater-Fernández y Díaz-Cama, 2020, p. 1279). Las bajas pensiones con las que cuentan las personas mayores no les permiten contar con esta herramienta que facilita el diario vivir de las personas.

Sin embargo, la brecha que toma mayor relevancia en la actualidad sociosanitaria es la "llamada "brecha gris", que refiere a la exclusión experimentada por las personas mayores" (Rivoir, Morales y Casamayou, 2019, p. 297). Un alto porcentaje de personas mayores tiene problemas de acceso o desconoce cómo utilizar estas herramientas en beneficio propio. Tenemos que ser conscientes de que esta es una brecha relevante para trabajar y debe ser superada en los próximos años, para ayudar a este tercio de la población del continente a tener un mejor acceso de conexión a internet trabajando con la alfabetización digital.

\section{Metodología}

Construir y obtener nuevos conocimientos para el trabajo dentro del acompañamiento socioemocional con personas mayores fue relevante en la situación vivenciada. El obtener una base teórica sólida para crear y compartir nuevos conocimientos se pudo considerar un reto frente al desconocimiento del virus. Trabajando sobre la marcha, el proyecto permitió observar y recoger las experiencias de los(as) participantes en este contexto social trabajando 
con los actores principales, lo que en este caso ayudó a comprender los efectos que pudieron sufrir las personas frente a momentos de una crisis inesperada.

La metodología utilizada durante este proceso fue el modelo sistémico de intervención, el cual permite analizar, pensar, identificar y diseñar estrategias para la acción. Aquí el elemento central de su teoría son las interacciones dentro de un sistema, incluyendo sus relaciones, estructuras e interdependencia, poniendo especial énfasis en las interacciones, transacciones e interrelaciones. Esta fue elegida principalmente porque los hechos y procesos no suceden de una forma aislada, la relación con el entorno afecta de forma positiva o negativa nuestras vidas y las de otros. Trabajando desde el modelo ecológico de Germain y Gitterman de 1980, donde la atención se centra en la transacción entre los individuos, grupos e instituciones, cuyo objetivo principal es hacer un diagnóstico de la problemática existente, siendo el sistema un elemento clave para una intervención profesional.

De esta forma, conversando con los actores se pudo observar en registros cómo las personas mayores comenzaron a decirnos sus problemas y malestares similares tales como: el sentimiento de soledad, tristeza, angustia, pena, el sentirse indefensos, rabia o ira como los principales elementos encontrados. Para la recolección de estos datos, se trabajó principalmente con fuentes primarias mediante llamadas telefónicas que fueron detectados con herramientas como: registros escritos, talleres del grupo de envejecimiento-vejez y entrevistas telefónicas. Estas técnicas permitieron observar y recoger cada experiencia de las personas mayores que participaron, además de las experiencias de cada estudiante, siendo fundamentales para recoger la información necesaria para llevar a cabo la sistematización de experiencia.

\section{Hallazgos}

\subsection{Resultados de la experiencia de trabajo en el proyecto}

Los resultados fueron recogidos desde las propias conversaciones que se mantuvieron con las personas mayores y estudiantes en cada reunión del grupo de estudio y trabajo, donde ellos comentaban lo comunicado por las personas con que se comunicaban semanalmente, junto a la propia experiencia obtenida de las llamadas telefónicas, tomando en cuenta cada uno de los efectos positivos o negativos encontrados en estas cuarentenas.

Se realizaron llamadas a 7 personas mayores de las cuales 5 son mujeres mayores de 60 años y 2 son hombres mayores de 60 años, presentando los resultados que se muestran en la Tabla 1. 
Aedo-Neira

Tabla 1. De resultado de llamadas telefónicas realizadas por las estudiantes del grupo de trabajo y estudio envejecimiento y vejez.

\begin{tabular}{|c|c|c|c|c|c|c|}
\hline & Edad & $\begin{array}{l}\text { ¿Con } \\
\text { quién } \\
\text { vive? }\end{array}$ & $\begin{array}{l}\text { Redes de } \\
\text { apoyo }\end{array}$ & $\begin{array}{l}\text { Actividades antes y } \\
\text { después del COVID- } \\
19\end{array}$ & $\begin{array}{l}\text { Medios de } \\
\text { contactos }\end{array}$ & $\begin{array}{l}\text { Sentimientos y } \\
\text { emociones }\end{array}$ \\
\hline W. L. & 81 & $\begin{array}{l}\text { Vive } \\
\text { sola en } \\
\text { su } \\
\text { hogar }\end{array}$ & $\begin{array}{l}\text { Cuenta con el } \\
\text { apoyo de } \\
\text { *Amigos } \\
\text { *Sobrinos } \\
\text { *Hermana } \\
\text { Por la } \\
\text { pandemia ella } \\
\text { necesita } \\
\text { ayuda de } \\
\text { terceros para } \\
\text { realizar ciertas } \\
\text { acciones. }\end{array}$ & $\begin{array}{l}\text { Antes: } \\
\text { *Asistir a la iglesia } \\
\text { *Participación como } \\
\text { profesora invitada en } \\
\text { seminarios o charlas } \\
\text { Después } \\
\text { *Leer } \\
\text { *Escuchar música. }\end{array}$ & $\begin{array}{l}\text { *Visitas de } \\
\text { amigos/as } \\
\text { *Llamadas } \\
\text { telefónicas } \\
\text { familia y } \\
\text { amistades } \\
\text { No le gustan } \\
\text { las redes } \\
\text { sociales. }\end{array}$ & $\begin{array}{l}\text { *Pena } \\
\text { *Rabia por la } \\
\text { indolencia mostrada } \\
\text { por la gente frente la } \\
\text { pandemia } \\
\text { *Frustración } \\
\text { *Preocupación } \\
\text { *Admiración por los } \\
\text { y las profesionales } \\
\text { de salud. }\end{array}$ \\
\hline A. $\mathrm{H}$. & 80 & $\begin{array}{l}\text { Vive } \\
\text { con su } \\
\text { hija y } \\
\text { nieta }\end{array}$ & $\begin{array}{l}\text { *Asociación } \\
\text { de jubilados } \\
\text { UCT } \\
\text { *Familia } \\
\text { Realiza sus } \\
\text { quehaceres de } \\
\text { forma } \\
\text { autónoma. }\end{array}$ & $\begin{array}{l}\text { Antes: } \\
\text { *Reuniones con } \\
\text { personas de la } \\
\text { asociación de } \\
\text { jubilados de la UCT. } \\
\text { Después: } \\
\text { *Una vez a la semana } \\
\text { se va a su campo } \\
\text { donde siembra trigo, } \\
\text { avena y lupino. } \\
\text { *Permanece gran } \\
\text { parte del tiempo en } \\
\text { casa. }\end{array}$ & $\begin{array}{l}\text { *Llamadas } \\
\text { telefónicas } \\
\text { A veces } \\
\text { presenta mala } \\
\text { señal } \\
\text { telefónica. }\end{array}$ & $\begin{array}{l}\text { *Angustia } \\
\text { *Preocupación por } \\
\text { sus seres más } \\
\text { cercanos } \\
\text { *Inquietud } \\
\text { *Pensamiento de que } \\
\text { se está creando una } \\
\text { nueva etapa que nos } \\
\text { enseña a vivir y } \\
\text { apreciar nuestras } \\
\text { vidas. } \\
\text { *Pena por el } \\
\text { individualismo de } \\
\text { las personas. }\end{array}$ \\
\hline Y. H. & 74 & $\begin{array}{l}\text { Vive } \\
\text { sola en } \\
\text { su } \\
\text { hogar }\end{array}$ & $\begin{array}{l}\text { *Hijos } \\
\text { *Iglesia } \\
\text { *CESFAM de } \\
\text { su comuna. } \\
\text { Cuenta con el } \\
\text { apoyo de su } \\
\text { hija y yerno } \\
\text { quienes la } \\
\text { ayudan con } \\
\text { las compras } \\
\text { del mes y } \\
\text { otros. }\end{array}$ & $\begin{array}{l}\text { Antes: } \\
\text { *Integrantes de la } \\
\text { mesa por los derechos } \\
\text { de las personas } \\
\text { mayores (PAM) } \\
\text { *Visita distintos } \\
\text { lugares con sus } \\
\text { amigas } \\
\text { *El encierro ha } \\
\text { afectado su } \\
\text { movilidad } \\
\text { Después: } \\
\text { *Cocinar } \\
\text { *Trabaja en sus } \\
\text { manualidades con } \\
\text { fieltro } \\
\text { *Escucha música }\end{array}$ & $\begin{array}{l}\text { *Recibe visitas } \\
\text { de su hija } \\
\text { *recibe } \\
\text { llamadas } \\
\text { telefónicas. } \\
\text { Se siente } \\
\text { aislada por no } \\
\text { manejar bien } \\
\text { los medios } \\
\text { digitales y por } \\
\text { el poco } \\
\text { contacto que } \\
\text { puede tener } \\
\text { con sus seres } \\
\text { queridos. }\end{array}$ & $\begin{array}{l}\text { *Ha tenido } \\
\text { momentos de } \\
\text { tranquilidad pero al } \\
\text { mismo tiempo ha } \\
\text { presentado } \\
\text { sentimientos que la } \\
\text { abruman } \\
\text { *Tristeza } \\
\text { *Inquietud } \\
\text { *Soledad }\end{array}$ \\
\hline
\end{tabular}




\begin{tabular}{|c|c|c|c|c|c|c|}
\hline & & & & & & Aedo-Neira \\
\hline F. P. & 68 & $\begin{array}{l}\text { Vive } \\
\text { con su } \\
\text { esposo }\end{array}$ & $\begin{array}{l}\text { *Familia } \\
\text { *Amigos } \\
\text { *Iglesia } \\
\text { *Junta de } \\
\text { vecinos } \\
\text { *Asociación } \\
\text { de adultos } \\
\text { mayores. }\end{array}$ & $\begin{array}{l}\text { Antes: } \\
\text { *Trabajaba en su } \\
\text { jardín } \\
\text { *Actividad física } \\
\text { *Junta de vecinos } \\
\text { Después: } \\
\text { *Busca diferentes } \\
\text { actividades que } \\
\text { pueda hacer para } \\
\text { evitar la rutina } \\
\text { *Asociación de } \\
\text { adultos mayores } \\
\text { donde se conectan } \\
\text { por zoom }\end{array}$ & $\begin{array}{l}{ }^{*} \text { Celular } \\
{ }^{*} \text { Video } \\
\text { llamadas con } \\
\text { sus familiares } \\
\text { Mejor manejo } \\
\text { de TICs. }\end{array}$ & $\begin{array}{l}\text { *Tranquilidad al } \\
\text { estar junto su esposo } \\
\text { *Tristeza por las } \\
\text { personas que han } \\
\text { perdido a sus seres } \\
\text { queridos } \\
\text { *Solidaridad } \\
\text { "Preocupación por } \\
\text { su salud mental y la } \\
\text { de su esposo. }\end{array}$ \\
\hline M. P. & 83 & $\begin{array}{l}\text { Con su } \\
\text { esposa } \\
\text { e hija }\end{array}$ & $\begin{array}{l}\text { *Apoyo de la } \\
\text { Mesa de } \\
\text { Personas } \\
\text { Mayores } \\
\text { *Hijos e hijas } \\
\text { *Nietos }\end{array}$ & $\begin{array}{l}\text { Antes: } \\
\text { *Reuniones y juntas } \\
\text { con los miembros de } \\
\text { la Mesa de Personas } \\
\text { Mayores } \\
\text { *Miembro junta de } \\
\text { escritores } \\
\text { Después: } \\
\text { *Terminado los } \\
\text { últimos poemas de su } \\
\text { libro (Debido a la } \\
\text { pandemia el } \\
\text { lanzamiento de este } \\
\text { se vio postergado) }\end{array}$ & $\begin{array}{l}\text { *Recibe } \\
\text { llamadas } \\
\text { telefónicas } \\
\text { No maneja } \\
\text { bien los } \\
\text { medios } \\
\text { digitales y } \\
\text { cuenta con la } \\
\text { ayuda de su } \\
\text { hija para } \\
\text { lograr utilizar } \\
\text { estas. }\end{array}$ & $\begin{array}{l}\text { *Se siente } \\
\text { preocupado } \\
\text { *Presenta cierta } \\
\text { desconfianza frente a } \\
\text { las cifras entregadas } \\
\text { sobre el virus. }\end{array}$ \\
\hline $\begin{array}{l}\text { H. } \\
\text { SM. }\end{array}$ & 91 & $\begin{array}{l}\text { Vive } \\
\text { sola } \\
\text { pero } \\
\text { desde la } \\
\text { llegada } \\
\text { del } \\
\text { virus } \\
\text { vive } \\
\text { con su } \\
\text { nieto }\end{array}$ & $\begin{array}{l}{ }^{*} \text { Cuenta con } \\
\text { sus } 5 \text { hijos/as } \\
\text { y nieto } \\
{ }^{*} \text { Cuenta con el } \\
\text { apoyo del } \\
\text { CESFAM } \\
\text { *Junta de } \\
\text { vecinos y la su } \\
\text { presidenta }\end{array}$ & $\begin{array}{l}\text { Antes: } \\
\text { *Actividades } \\
\text { limitadas debido a su } \\
\text { estado de salud } \\
\text { Después: } \\
\text { *Realiza trabajo en } \\
\text { tejidos } \\
\text { *Jardinería }\end{array}$ & $\begin{array}{l}{ }^{*} \text { Recibe } \\
\text { llamadas } \\
\text { telefónicas } \\
\text { No maneja } \\
\text { bien los } \\
\text { medios } \\
\text { digitales. }\end{array}$ & $\begin{array}{l}{ }^{*} \text { El vivir con su nieto } \\
\text { le da seguridad } \\
{ }^{*} \text { Decaimiento } \\
{ }^{*} \text { Cansancio } \\
{ }^{*} \text { Orgullo por sus } \\
\text { hijos. }\end{array}$ \\
\hline G. L. & 79 & $\begin{array}{l}\text { Vive } \\
\text { sola }\end{array}$ & $\begin{array}{l}\text { *Hijos } \\
{ }^{*} \text { cuenta con la } \\
\text { ayuda de la } \\
\text { presidenta de } \\
\text { la junta de } \\
\text { vecinos } \\
\text { *Apoyo del } \\
\text { CESFAM }\end{array}$ & $\begin{array}{l}\text { Antes: } \\
\text { *Clubes de las } \\
\text { personas mayores } \\
\text { *Junta de vecinos } \\
\text { Después: } \\
\text { *Lectura } \\
\text { *Tejido } \\
\text { *Etc. }\end{array}$ & $\begin{array}{l}\text { *Recibe } \\
\text { llamadas } \\
\text { telefónicas } \\
\text { No maneja } \\
\text { bien los } \\
\text { medios } \\
\text { digitales. }\end{array}$ & $\begin{array}{l}\text { *Pena } \\
\text { *Cansancio } \\
\text { *Angustia } \\
\text { *Depresión } \\
\text { (Esta comenzó } \\
\text { después de la } \\
\text { pérdida de su } \\
\text { marido e hijo a causa } \\
\text { del cáncer). }\end{array}$ \\
\hline
\end{tabular}

Fuente: elaboración propia. 
Nota: La tabla anterior muestra datos recolectados en las reuniones semanales del grupo de estudio y trabajo. En esta sistematización de experiencias desarrollada en el proyecto de acompañamiento socioemocional; se muestran los datos de cómo ellos(as) vivieron el periodo de cuarentenas durante la pandemia.

Con lo anterior, se dividió esta experiencia en tres momentos relevantes para la construcción científica del proyecto, lo que permitió reflexionar sobre los aspectos más importantes para ser estudiados en este proceso de trabajo y estudio.

Construyendo los pilares del acompañamiento: luego de una construcción teórica en agosto, comenzaron las primeras llamadas y conversaciones que nos llevaron a formar lo que sería el proyecto de acompañamiento. Con el fin de recuperar, tanto el capital social como cultural de las personas mayores, además de poder brindar el apoyo socioemocional correspondiente en los meses de proyecto lo cual fue fundamental a la hora de trabajar los temas de aislamiento y brechas digitales.

Podemos decir que "las personas que están en aislamiento (...) con movilidad restringida y pobre contacto (...) son vulnerables a presentar complicaciones (...) que van desde síntomas aislados hasta el desarrollo de un trastorno mental como insomnio, ansiedad, depresión" (Ramírez-Ortiz, Castro-Quintero, Lerma-Córdoba, Yela-Ceballos \& Escobar-Córdoba, 2020, p. 4). Los principales síntomas identificados, en las llamadas a causa del encierro, son principalmente los mencionados anteriormente. De esta manera, las brechas digitales se convierten en un problema, debido a la incorporación de nuevas tecnologías o a la falta de acceso a estas, al momento de comunicarse con otras personas a la distancia por medio de las redes y herramientas que permiten simular una comunicación presencial, muchas personas mayores no saben cómo utilizar estas herramientas.

Generar la instancia de construcción de confianza mutua por medio de las llamadas telefónicas fue relevante para llevar a cabo las siguientes etapas de trabajo que permitieron generar una imagen global en estas circunstancias sociosanitarias, más aún cuando las personas vivencian una separación física, en la que para poder hablar o comunicarse con sus amistades $\mathrm{y}$ familiares necesitaban un intermediario como un celular o una computadora que los mantuviera unidos dentro de la realidad sociosanitaria que se encontraban viviendo. El participar de este acompañamiento vía telefónica fue de gran ayuda para la salud mental de cada persona en las distintas situaciones de aislamiento que ellos se encontraban viviendo de manera solitaria en sus hogares.

Construyendo confianza en tiempos de crisis: el segundo grupo estaba compuesto por personas que presentaban la disponibilidad y una falta de red de apoyo sólida que los acompañara durante la cuarentena. Dentro de este grupo, se encuentra la señora G. L. quién vive sola y pasa por una depresión debido a la muerte de uno de sus hijos hace unos años 
atrás por cáncer, enfermedad que también causó la muerte de su esposo en el año 2019. Antes de la pandemia, ella contaba con la ayuda directa de la presidenta de la junta de vecinos y la de un hijo que la acompañaba todos los días a la hora de almuerzo, pero a causa de las cuarentenas, ellos no podían estar tan presentes para ella como antes de la pandemia, aun así intentaban hacerla sentir acompañada.

Otro participante a destacar es el señor $\boldsymbol{M}$. $\boldsymbol{P}$. Él estaba consciente de la importancia de las relaciones intergeneracionales y estaba de acuerdo con que estos espacios son necesarios para compartir experiencias con los más jóvenes, lo que también les será de utilidad como parte de su formación académica, en particular a las estudiantes que realizaban sus prácticas en tiempos de pandemia.

A medida que pasaban las sesiones, se crearon vínculos de confianza y respeto mutuo lo que permitió que la comunicación fuese más fluida entre las estudiantes en práctica y los(as) participantes del proyecto de acompañamiento telefónico. Así, dentro de la sesión 1 y 2, las personas mayores fueron contando más sobre sus experiencias de vida y sus vivencias durante la pandemia, y al mismo tiempo se generaron las instancias para que ellos(as) escucharan a las estudiantes sobre cómo ellas viven estos meses de encierro y estudio. Se compartieron anécdotas y experiencias que permitieron reforzar las instancias intergeneracionales que fomentan el envejecimiento activo, optimizando las oportunidades de bienestar social y mental de los mayores creando espacios que mejoran la calidad de vida de las personas.

De la misma manera, ellos comentaban cómo antes de la pandemia participaban en actividades lúdicas, por ejemplo: junta de vecinos, reuniones de la asociación de jubilados de la UCT, asociación de adultos mayores, club de escritura, iglesia, clubes comunitarios, entre otras. En muchos casos, las personas mayores invitaron y propusieron a las estudiantes conocerse en persona, para poder poner un rostro al nombre una vez terminaran las prohibiciones impuestas por la pandemia.

Sembrando y cosechando conocimientos: en la sesión 3 y 4 donde ya existía confianza con las personas mayores, se comenzó a recoger los conocimientos que poseen los mayores, tanto en el capital social como cultural que estos representan y que tienen para compartir con las estudiantes, además de que ellos(as) también estaban dispuestos a recibir los conocimientos de las estudiantes. En este punto, se compartieron las experiencias de cómo se está viviendo estos meses dentro de la crisis sociosanitaria y cómo de a poco se intenta retomar la normalidad.

Por ejemplo, el Señor $A$. $H$. estaba pasando esta crisis junto a su hija y única nieta. Él desde su perspectiva aconseja a las generaciones más jóvenes de cómo deben vivir el proceso de envejecimiento con una actitud positiva sin deprimirse, ya que, llegar a esta 
etapa de la vida es un privilegio pero se debe saber aprovechar la oportunidad de escuchar los consejos y los saberes de las personas mayores. Él nos comenta la visión que tiene el Pueblo Mapuche, presente en la Araucanía, con respecto a las personas mayores, quienes son valorados y respetados por las generaciones más jóvenes por sus conocimientos y saberes.

Para él, este proyecto fue una experiencia importante, él menciono que existen épocas que nadie lo llama y se sintió importante al poder participar del acompañamiento telefónico. Para él ha sido una experiencia nueva donde también conoció a quien estaba a cargo de sus llamadas y de igual manera, la encargada de realizar las llamadas agradeció este espacio donde pudo aprender de don $\boldsymbol{A}$. $\boldsymbol{H}$.

La Señora $Y . H$. ., por su parte. habló de cómo muchas veces la sociedad erróneamente infantiliza a las personas mayores al llegar a esta etapa de la vida. De acuerdo a sus propias palabras, los convierten en personas incapaces de valerse por sí mismas o los limitan de poder realizar acciones como cualquier otra persona. Muchas veces, esto se hace de manera inconsciente, se pasa por alto que ellos son personas adultas, y se les inhabilita como personas de derechos que pueden valerse por sí mismos/as. También existen personas más jóvenes que caen en lo que corresponde al edadismo que es, "el profundo malestar de los jóvenes y adultos de mediana edad frente a la inutilidad (...) de la vida que la vejez pone de manifiesto en el imaginario, lo que se expresa a la larga en un rechazo personal" (Huenchuan, 2018, p. 90).

Es necesario reconocer el capital social y cultural que poseen los mayores a partir de su experiencia vital. Esta experiencia sirvió para nutrir las vivencias de los más jóvenes al haber intercambios de saberes que se lograron al convivir con el otro, lo que es enriquecedor para las personas que están dispuestas a participar escuchando y aprendiendo de otros que están dispuestos a enseñar.

La preocupación principal en estos tiempos es el impacto producido a nivel psicológico y social en las personas mayores debido a la pandemia, la cual "no tiene precedentes en la vida de los adultos mayores: la cuarentena obligatoria y la necesidad de distanciamiento social llevó al cierre de plazas, hospitales (...), a la cancelación de actividades recreativas, al cierre de negocios" (Schapira, 2020, p. 2). Por esta razón es importante poner atención a los estados de ánimo como fatiga, cansancio y depresión, lo que genera un gran interés al analizar cómo este grupo etario pasó sus días entre las cuarentenas y el aislamiento.

En el caso de las personas que participaron en estas entrevistas, se pudo apreciar que contaban con el apoyo de un familiar que los cuidaba, como por ejemplo un hijo o hija, un nieto o nieta y en algunos casos su cónyuge. Estas personas son de gran importancia, ya que 
ellos(as) llevan el peso y la preocupación de que sus familiares se sientan resguardados, sin olvidar que cultural e históricamente, el rol del cuidador recae en un "miembro del grupo familiar, el que generalmente (...) recae en una de las mujeres que puede ocupar ya sea el rol de madre, abuela, hija, hermana, tía u otro, en relación a la persona cuidada" (Ministerio de Desarrollo Social y Familia [SENADIS], 2019, p. 5). En la actualidad, el rol del cuidador continúa teniendo una imagen femenina, recayendo la responsabilidad en la mujer, quien debe ser la encargada de cuidar a su padre, madre, hermanos(as) o hijos(as) en caso de existir una situación en la que una persona necesite de cuidados especiales. Sin embargo, en los resultados previamente analizados, se puede ver que tanto hombres como mujeres cumplen el rol de cuidador, lo que representa el cambio social y cultural que estamos viviendo en la sociedad actual, donde los roles son compartidos dentro de los miembros de las familias.

Uno de los informes del COVID-19 escrito por la Comisión Económica para América Latina y el Caribe (CEPAL, 2020a) nos habla de cómo:

Este confinamiento obligatorio en el hogar tiene consecuencias en la salud mental (...) pues afecta la comunicación con sus familiares o amigos, debilita sus redes de apoyo social y provoca un cambio en las rutinas de las actividades que realizan a diario. La sensación de inseguridad ante el contagio se acentúa con los sentimientos de soledad y abandono. (p. 22)

Las personas mayores durante la pandemia no contaron con una red de apoyo informal sólida que permitiera acompañarlos en este periodo, esto incrementó la sensación de inseguridad, soledad y abandono al no poder recibir visitas que les brinde una contención emocional positiva.

Lo que es esencial teniendo en mente a los mayores, quienes en estos meses han tenido pensamientos y sentimientos negativos frente a lo que les tocó vivir durante este año, siendo importante el poder apoyar en el desarrollo de programas y beneficios para sobrellevar de mejor manera los efectos de la pandemia, trabajando en entregar herramientas que sean positivas para cada individuo que les permita superar las adversidades negativas que viven.

Con el proyecto se innovó de una forma positiva en la vida de quienes participaron del acompañamiento telefónico, junto a las herramientas tecnológicas y de conectividad que ayudaron a desarrollar el proyecto con un nuevo enfoque, la capacidad de reinventarse y sobreponerse ante las adversidades saliendo de nuestra zona de confort y atreverse a hacer cosas distintas que entreguen mejores resultados. 


\subsection{Desafíos para el Trabajo Social}

Frente al complejo año vivido por la población que se vio afectada por el brote de un nuevo virus que causó la muerte de millones de personas a nivel mundial, logramos apreciar las necesidades de la sociedad frente a una crisis que nos pueda afectar repentinamente en distintos niveles. Quizás, la falla en la rapidez de acciones de los distintos gobiernos o la falta de información sobre el virus que nos abordó de la nada, produjo que la incertidumbre y el miedo tomaran por sorpresa principalmente a un grupo etario que enfrentó mayores dificultades al momento del contagio. En este grupo, se encuentran aquellas personas mayores de 65 años, quienes en muchos casos presentaban enfermedades de base como hipertensión, problemas respiratorios, afecciones cardiacas o depresión, lo que dificultó aún más la realidad social que estaban viviendo.

Como bien sabemos, en la experiencia de trabajo con personas mayores dentro del contexto sociosanitario actual, se pudo observar que el trabajo con ellos(as) y sus familias que se puede hacer desde la profesión es de gran importancia, más aún en la situación que nos encontramos viviendo, debido a que esto puede asegurar una mejor calidad de vida tanto en su salud mental como física pues:

Los trabajadores sociales sabemos que, como toda enfermedad, el Covid-19 es una enfermedad social, es decir que no puede ser pensada sólo desde la medicina (...) la capacidad del Trabajo Social de comprender el territorio desde sus diferentes expresiones, aporta, en este contexto, la posibilidad de trabajar en la recuperación de lazos sociales. (Carballeda, 2020, p. 1)

Dentro de los aspectos centrales, podemos observar cómo desde la profesión tenemos la capacidad de desarrollarnos tanto en el ámbito social, familiar y comunitario con las personas, siendo participes y generando un cambio social frente a estas dificultades que se viven hoy en día, lo que permite el cambio de vida de las personas mayores frente a la situación actual ayudando a mejorar la calidad de vida de cada individuo dentro del contexto social.

El trabajo que se puede realizar con personas mayores en tiempos de pandemia es esencial, más aún con aquellas personas que están solos(as). La soledad no deseada es "uno de los principales problemas a los que se enfrenta nuestra sociedad. En este sentido hemos detectado que las personas mayores vuelven a ser un colectivo vulnerable (...) la dependencia y la discapacidad se suman las complicaciones propias de una soledad" (Yusta-Tirado, 2019, p. 40). En la etapa de la vejez, la soledad produce varios efectos negativos, es por esto que es importante validar a las personas mayores en sus opiniones y derechos ya que los ayuda a tener un envejecimiento positivo. 
Por esta razón, generar proyectos con el fin de mejorar las condiciones y la calidad de vida de las personas mayores, se transforma en una necesidad fundamental, promover el envejecimiento activo "que mejorará la salud y la participación de las poblaciones que están envejeciendo, asegurando, al mismo tiempo, que los ancianos tienen la adecuada seguridad, protección y cuidado cuando requieran asistencia" (Organización Mundial de la Salud [OMS], 2002, p. 103). Resguardar la seguridad física y mental de las personas mayores es importante para asegurar una mejor forma de envejecer en la sociedad protegiendo sus derechos y entregando una adecuada seguridad, protección y cuidados; además de fortalecer las relaciones intergeneracionales que favorecen los espacios donde los mayores pueden participar, capacitarse y adquirir nuevos conocimientos. Es en este punto, cuando los trabajadores sociales pueden desarrollar y crear espacios que permitan un envejecimiento positivo, ayudando a que ellos se conecten y aprendan lo que beneficia a todas las generaciones, recuperando el tejido social entendido como un "conjunto de relaciones efectivas que determinan las formas particulares de ser, producir, interactuar y proyectarse en los ámbitos familiar, comunitario, laboral y ciudadano" (Guzmán-Olea et al., 2015, p.13).

Se debe percibir lo que ellos representan en los distintos ámbitos y espacios que ocupan con el valor correspondiente; ellos aún tienen mucho que aportar desde su sabiduría, la cual es importante en la trasmisión de saberes. Estas relaciones no solo son positivas para las personas mayores, vemos que también lo son para los más jóvenes, que al interactuar con ellos logran un aprendizaje nutritivo para las generaciones más jóvenes. Pero para que estos aprendizajes sean enriquecedores, las personas mayores deben estar dispuestas a escuchar a la juventud, que está llena de nuevas ideas, y la juventud tiene que estar dispuesta a escuchar a la sabiduría que les aporta la edad; las relaciones intergeneracionales solo funcionan cuando ambas generaciones están dispuestas a escuchar al otro.

La intergeneracionalidad, como proceso bidireccional de beneficio mutuo, nos exige tener presentes las demandas y necesidades de unos y otros desde la consideración de que ambos colectivos son un recurso humano, económico, social y cultural de inestimable valor para sus familias y comunidades. (Riaño-Barón, 2017, p. 4)

Los beneficios mutuos que permiten estos espacios logran efectos positivos en la vida de los que participan en los mismos, pero cuando los mayores son quienes participan obtienen una mejor salud mental, incrementan su autoestima y se sientan más activos mejorando su calidad de vida.

Como disciplina, debemos mantener el enfoque en fomentar el envejecimiento activo como un: 
Proceso de optimización de las oportunidades de salud, participación y seguridad con el fin de mejorar la calidad de vida a medida que las personas envejecen; lo que les permite realizar su potencial de bienestar físico, social y mental a lo largo de todo su curso vital y participar en la sociedad de acuerdo con sus necesidades. (Martínez-Pérez, González-Aragón, Castellón-León y González-Aguiar, 2018, p. 63)

En este punto, el Trabajo Social puede producir instancias que participen en la creación de espacios que proporcionen protección, seguridad y cuidados adecuados a su calidad de vida y fomenten lazos intergeneracionales que favorezcan el envejecimiento mejorando la misma. En parte, esto fue lo que intentó generar el proyecto de acompañamiento, una instancia donde dos generaciones fuesen un aporte para la otra persona, en un momento de necesidad donde la salud mental estaba siendo señalada por la cantidad de noticias negativas que causaban un ambiente de pánico generalizado en la población.

La innovación de crear nuevas formas de intervención y llevar a cabo las prácticas fuera de una institución física y el uso de las tecnologías en favor de la propia labor del profesional es una de las necesidades primordiales desde la profesión, donde los trabajadores sociales se han caracterizado por el trabajo de campo presencial con los actores sociales y la comunidad interactuando en beneficio de cada persona. Es por esto que modificar la forma de trabajo con las personas es una necesidad actual, más aún dentro de las prácticas de estudiantes, quienes se vieron con las manos cruzadas al momento de trabajar, por falta de centros físicos para acompañar a los mayores. Aquí el cambio de modalidad de trabajo resultó ser un desafío, ya que nos vimos obligados a pensar más allá y crear sobre la marcha cambiar las formas de hacer prácticas.

\section{Conclusiones}

Este año las dificultades que se presentaron al momento de realizar las prácticas presenciales fueron complejas, el ver cómo simplemente las personas responsables de las practicas cerraron las oportunidades y las puertas a cada estudiante para el trabajo correspondiente, pero el innovar en la forma de hacer prácticas dentro de la carrera permitió que cada estudiante generara y produjera nuevos conocimientos favorables para su crecimiento profesional, donde el interés personal de sistematizar nace de estudiar las dificultades que existen entre el aislamiento y los medios digitales por parte de los mayores, quienes pueden ver estos medios como una solución o una dificultad frente al aislamiento que ellos vivieron en estos últimos meses, lo que ha afectado su estado de ánimo, incrementando factores como el estrés y ansiedad. 
En el mes de junio 2020, el gobierno de Chile lanzó un programa por medio del MINSAL para apoyar la salud mental durante la pandemia llamado "SaludableMente", este tiene por objetivo fortalecer tanto los sectores públicos como privados en el tratamiento de salud mental, más ahora que el encierro ha acentuado la necesidad que presenta la población cuando se trata de esta temática.

Para sistematizar, se tomaron en cuenta los criterios considerados en la formación del proyecto de acompañamiento, tales como el consentimiento informado que se comunicó a las personas mayores al momento de iniciar las llamadas, para poder reproducir sus conocimientos y experiencias con otras personas recolectando la información mediante las entrevistas, con el fin de levantar esta información para llevar una propuesta al voluntariado de la universidad para formar un programa permanente que acompañe a las personas mayores, no tan solo en la época de pandemia sino de una duración indefinida que sea un aporte a la comunidad.

Finalmente, es importante dejar de lado el concepto de personas "indefensas" cuando hablamos de personas mayores, muchos son infantilizados aun cuando ellos son capaces de realizar sus actividades sin necesidad de apoyo, exceptuando a quienes cuentan con movilidad reducida que no les permite hacer sus actividades diarias. Se debe tomar en cuenta la opinión de ellos para evitar la discriminación por edad que muchas veces invisibiliza a los mayores dentro de la sociedad. Muchas veces las personas mayores quedan aisladas socialmente debido a que se dejan de respetar sus derechos, cambiar el imaginario social que tienen las personas más jóvenes de las personas mayores crea una sociedad más inclusiva para los distintos grupos etarios.

El proyecto partió en un contexto de pandemia y aislamiento para dar voz a las personas mayores generando una mayor inclusión, dejando nuevas interrogantes sobre ¿Cómo fomentar nuevas herramientas de trabajo en la temática de envejecimiento?, además de abrir el cuestionamiento a la superación de las brechas digitales y exclusión, las cuales deben ser trabajadas desde la gerontología abriendo paso a un trabajo multidisciplinar efectivo. Crear futuros proyectos que intervengan e involucren a las personas mayores es importante y primordial, debe ser una preocupación de la agenda social de cada gobierno formar programas que logren equiparar el camino para que la calidad de vida de las personas, al llegar a una edad mayor, sea positiva y se cuente con todas las herramientas necesarias para un mejor envejecimiento. 


\section{Referencias bibliográficas}

Broche-Pérez, Y., Fernández-Castillo, E., y Reyes-Luzardo, D. A. (2020). Consecuencias psicológicas de la cuarentena y el aislamiento social durante la pandemia de COVID19. Revista Cubana de Salud Pública, 46(Supl. Esp.), e2488. Recuperado de http://www.revsaludpublica.sld.cu/index.php/spu/article/view/2488.

Carballeda, A. (2020). Apuntes sobre la intervención del Trabajo Social en tiempos de Pandemia de Covid-19.

Recuperado

de https://www.margen.org/pandemia/textos/carballeda2020.pdf.

Comisión Económica para América Latina y el Caribe [CEPAL]. (2020a). Desafíos para la protección de las personas mayores y sus derechos frente a la pandemia de COVID19. INFORMES COVID-19, (Diciembre), 1-34. Recuperado de https://repositorio.cepal.org/bitstream/handle/11362/46487/S2000723_es.pdf?seq uence $=1$ \&is Allowed $=y$.

Comisión Económica para América Latina y el Caribe [CEPAL]. (2020b). Universalizar el acceso a las tecnologías digitales para enfrentar los efectos del COVID-19. Informe Especial COVID-19, (7), 1-27. Recuperado de https://repositorio.cepal.org/bitstream/handle/11362/45938/4/S2000550_es.pdf.

Fundación País Digital. (2018). Estudio de Fundación País Digital: 72,7\% de los chilenos usan internet. Recuperado de https://paisdigital.org/2018/12/13/estudio-de-fundacionpais-digital-727-de-los-chilenos-usan-internet/.

Gajardo-Jauregui, J. (2015). Vejez y soledad: implicancias a partir de la construcción de la noción de riesgo. Acta bioethica, 21(2), 199-205. Recuperado de https:/ / www.scielo.cl/scielo.php?script=sci_arttext\&pid=S1726569X2015000200006\&lng=en\&nrm=iso\&tlng=en.

Guzmán-Olea, E., Maya-Pérez, E., López-Romero, D., Torres-Poveda, K., Madrid-Marina, V., Pimentel-Pérez, B. ... Agis-Juárez, R. (2017). Eficacia de un programa de empoderamiento en la capacidad de autocuidado de la salud en adultos mayores mexicanos jubilados. Salud $\mathcal{E}$ Sociedad, 8(1), 10-20. doi: 10.22199/S07187475.2017.0001.00001.

Huenchuan, S. (Ed.). (2018). Envejecimiento, personas mayores y Agenda 2030 para el Desarrollo Sostenible: perspectiva regional y de derechos humanos. Santiago, Chile: CEPAL. Recuperado de https:/ / repositorio.cepal.org/bitstream/handle/11362/44369/1/S1800629_es.pdf.

Lozano-Vargas, A. (2020). Impacto de la epidemia del Coronavirus (COVID-19) en la salud mental del personal de salud y en la población general de China. Revista de Neuro$\begin{array}{llll}\text { Psiquiatría, } & \text { 83(1), } & \text { Recuperado de }\end{array}$ http:/ / www.scielo.org.pe/pdf/rnp/v83n1/1609-7394-rnp-83-01-51.pdf.

Martínez-Pérez, T. J., González-Aragón, C. M., Castellón-León, G., y González-Aguiar, B. (2018). El envejecimiento, la vejez y la calidad de vida: ¿éxito o dificultad? Revista Finlay, 8(1). Recuperado de http://scielo.sld.cu/pdf/rf/v8n1/rf07108.pdf. 
Mesa Social Covid-19. (2020). Salud mental en situación de pandemia. Documento para Mesa Social Covid-19. Recuperado de https://cdn.digital.gob.cl/public_files/Campa\%C3\%B1as/CoronaVirus/documentos/Salud_Mental_V2.pdf.

Ministerio de Desarrollo Social y Familia [SENADIS]. (2019). Feminización del cuidado y personas con discapacidad. Diagnóstico desde fuentes y registros administrativos. Recuperado de https:/ / www.senadis.gob.cl/descarga/i/6167.

Organización Mundial de la Salud [OMS]. (2002). Envejecimiento activo: un marco político. Revista Española de Geriatría y Gerontología, 37(S2),74-105. Recuperado de http:/ / envejecimiento.csic.es/documentos/documentos/oms-envejecimiento01.pdf.

Pontificia Universidad Católica de Chile. (2020). Adultos mayores en cuarentena: Cuidado vs. libertad personal. Recuperado de https://www.uc.cl/noticias/adultos-mayores-encuarentena-cuidado-vs-libertad-personal/.

Ramírez-Ortiz, J., Castro-Quintero, D., Lerma-Córdoba, C., Yela-Ceballos, F., \& EscobarCórdoba, F. (2020). Mental health consequences of the COVID-19 pandemic associated with social isolation. Colombian Journal of Anesthesiology. 48(4), e930. doi: 10.5554/22562087.e930.

Riaño-Barón, G. M. (2017). Relaciones intergeneracionales en Iberoamérica. Boletín del Programa Iberoamericano de Cooperación sobre Adultos Mayores, (13), 4-4. Recuperado de https://gerontologia.org/portal/archivosUpload/uploadManual/Intergeneracional _BOLETIN_13-DEF-compressed.pdf.

Rivoir, A., Morales, M. J., y Casamayou, A. (2019). Usos y percepciones de las tecnologías digitales en personas mayores. Limitaciones y beneficios para su calidad de vida. Revista Austral de Ciencias Sociales, (36), 295-313. doi: 10.4206/rev.austral.cienc.soc.2019.n36-15.

Sabater-Fernández, C., Martínez-Lorea, I., y Campión, R. (2017). La Tecnosocialidad: el papel de las TIC en las relaciones sociales. RLCS, Revista Latina de Comunicación Social, 72, 1.592-1.607. doi: 10.4185/RLCS-2017-1236.

Sabater-Fernández, C., y Díaz-Cama, M. (diciembre, 2020). Los tiempos del Covid-19 acentúan la brecha digital como brecha social en La Rioja. En Edunovatic 2020. Conference Proceedings. 5th Virtual International Conference on Education, Innovation and ICT. REDINE (Red de Investigación e Innovación Educativa), Madrid, España. Recuperado de

http://www.edunovatic.org/wpcontent/uploads/2021/02/EDUNOVATIC20.pdf.

Schapira, M. (2020) Impacto psicosocial de la pandemia por COVID-19 en adultos mayores con demencia y sus cuidadores. Revista Argentina de Salud Pública, 12(Suplemento Covid-19), e4. Recuperado de https:/ / rasp.msal.gov.ar/rasp/articulos/vol12supl/REV-Schapirae4.pdf. 
Aedo-Neira

Servicio nacional del adulto mayor - SENAMA (2019). Recuperado de: http:// www.senama.gob.cl/noticias/ante-altos-indices-de-suicidio-senama-yminsal-impulsan-mesa-de-salud-mental-que-entregara-propuesta.

Subsecretaria de evaluación social - División Observatorio Social (2020). Documento de resultados: Personas mayores, envejecimiento y cuidados. http:/ / observatorio.ministeriodesarrollosocial.gob.cl/storage/docs/grupospoblacion/Documento_de_resultados_Personas_mayores_envejecimiento_y_cuidad os_31.07.2020.pdf.

Yusta-Tirado, R. (2019). La soledad no deseada en el ámbito de la Gerontología. Trabajo Social Hoy, (88) 25-42. doi: 10.12960/TSH.2019.0014. 


\section{OTROS ARTÍCULOS DE PROSPECTIVA No. 33}

\section{EDITORIAL}

El Paro Nacional en Colombia 2021: explosión social entre dinámicas estructurales y de coyuntura. Relevancia de la acción política y del diálogo en su desarrollo y transformación Adolfo Adrián Álvarez-Rodríguez

\section{ARTÍCULOS}

Organizaciones sociales de pobladores y prácticas de resistencia en contexto de pandemia COVID-19 en Chile

Patricia Castañeda-Meneses

Entre el aislamiento y las brechas digitales: sistematización de experiencia de acompañamiento socioemocional en personas mayores de Temuco, Chile, en tiempos de COVID-19

G. Bernarda Aedo-Neira

Percepción de apoyo social y calidad de vida: la visión de personas mayores chilenas en el contexto de pandemia durante el 2020

Claudia Elena Quiroga-Sanzana

Gabriela Rocío Parra-Monje

Camila Julia Moyano-Sepúlveda

Marco Alejandro Díaz-Bravo

A propósito del qué, cómo y para qué investigar en el campo de la justicia juvenil: La trastienda de un proceso de investigación en Rosario, Argentina Karina De Bella

Proyección social: reflexión sobre una experiencia virtual con adolescentes en época de pandemia en Sucre y Bolivar, Colombia

Claudia Yaneth Martínez-Mina
La intervención social mediante proyectos comunitarios en modalidad virtual en Mérida, México. Una perspectiva desde el Trabajo Social Claudia Isabel Tzec-Puch Amairani Aracelly Ceh-Alvarado Yanet Guadalupe González-Canul

Resignificación de los vínculos Sociales durante la pandemia de COVID-19: narrativas de personas que convergen en Conjuntos residenciales en Bogotá, Colombia

Andrea Marcela Reyes-García

Laura Daniela Molina-Ortiz

La paradoja de la familia doblemente recluida: clínica de una pandemia en Colombia

Norman Darío Moreno-Carmona

Juan José Cleves-Valencia

Ciencias sociales, mundo y pandemia: por un futuro posible

José Miguel Segura-Gutiérrez

Lina Paola Vásquez-Ávila

¿Qué es Trabajo Social? Los primeros vínculos de los estudiantes con la profesión: experiencias de Argentina, Brasil, Paraguay y Uruguay

Silvia Orieta Rivero-Rodríguez

Leonel Del Prado

Nidia Graciela Battilana-Amarilla

Rosilaine Coradini-Guilherme

Intervención profesional de trabajadores sociales de la universidad del Quindio, Colombia. Asuntos epistemológicos, metodológicos y ético-políticos

Ana María Gil-Ríos 
Reflexiones sobre la intervención social en lo rural: experiencias en el Magdalena Medio, Colombia

Claudia Milena Quijano-Mejía

Johana Linares-García

Construcción de rutas de atención integral a la convivencia escolar en Cali, Colombia: sistematización de la experiencia

Leidy Johana Prado-Montaño

Luz Helena López-Rodríguez

Alejandra Gutiérrez-Cárdenas

Experiencia del proceso de intervención familiar de los actores participantes en la Escuela para Familias del ICBF-Jamundí, Colombia Katherin Viviana Silva-Minotta

María José Forero-Izquierdo

Jimena del Pilar Jaramillo-Jaramillo

\section{RESEÑAS DE LIBROS}

Alerta global: políticas, movimientos sociales y futuros en disputa en tiempos de pandemia Jairo Crispín

El neoliberalismo como teología política. Habermas, Foucault, Dardot, Laval y la historia del capitalismo contemporáneo

José Francisco Desentis-Torres

La Reconceptualización del Trabajo Social en Colombia: Análisis histórico-crítico de las décadas de 1960-1970

Juan Pablo Sierra-Tapiro

ARTISTA INVITADO

Juan Camilo González

Prospectiva

\section{PROSPECTIVA}

Revista de Trabajo Social e Intervención Social

No. 33 • ene.-jun. 2022

e-ISSN: 2389-993X • Universidad del Valle 